\title{
Erythrocyte Alterations and Increased Cardiovascular Risk in Chronic Renal Failure
}

\author{
Mario Bonomini, ${ }^{1, *}$ Assunta Pandolfi, ${ }^{2}$ Vittorio Sirolli, ${ }^{1}$ Arduino Arduini, ${ }^{3}$ Lorenzo Di Liberato, ${ }^{1}$ and \\ Natalia Di Pietro ${ }^{2}$ \\ ${ }^{1}$ Unit of Nephrology and Dialysis, Department of Medicine, “SS. Annunziata” University Hospital, Chieti, Italy \\ ${ }^{2}$ Aging Research Center and Translational Medicine CeSI-MeT, “G. d'Annunzio” University, Chieti-Pescara, Italy \\ ${ }^{3}$ Department of Research and Development, Core Quest Sagl, Tecnopolo, Manno, Switzerland \\ "Corresponding author: Mario Bonomini, MD, Unit of Nephrology and Dialysis, Department of Medicine, G. d'Annunzio University, Via dei Vestini, 66013 Chieti, Italy. Tel: \\ +39-871540120, Fax: +39-871574736, E-mail: m.bonomini@nephro.unich.it
}

Received 2017 January 25; Accepted 2017 March 03.

\begin{abstract}
Patients suffering from chronic renal failure have a higher burden of cardiovascular events, which increases in a dose-dependent fashion as renal function worsens. Increased cardiovascular risk in these patients is thought to be mediated by the simultaneous presence of both traditional and non-traditional cardiovascular risk factors, the latter being associated with renal impairment. Red blood cells are usually considered as carries of nutrients for tissues and respiratory gases, less so as compartments essential to vascular integrity. However, erythrocyte number, size, and integrity seem to severely affect cardiovascular morbidity and mortality as established in recent clinical studies with large patient cohorts. In particular, the role of red blood cells in chronic renal failure tends only to be considered exclusively in relation to a change in their number. However, these cells in the uremic milieu are prone to many alterations, which may adversely affect the cardiovascular system. In this review, we highlight the main qualitative erythrocyte alterations that may have a pathophysiologic role in the elevated cardiovascular risk of chronic renal failure.
\end{abstract}

Keywords: Red Blood Cell, Renal Insufficiency, Phosphatidylserine, Nitric Oxide, Cardiovascular Disease, Endothelium, Uremia, Hemodialysis

\section{Context}

Cardiovascular (CV) disease is still the main cause of morbidity and mortality in chronic renal patients (1). The risk of $\mathrm{CV}$ events increases when the glomerular filtrate falls below $60 \mathrm{~mL} / \mathrm{min} / 1.73 \mathrm{~m}^{2}$ and gets steadily more pronounced as renal function diminishes, being especially high in patients on dialytic replacement therapy (1).

The traditional risk factors like aging, diabetes, hypertension, and dyslipidemia are highly prevalent in chronic renal failure (CRF) and add significantly to CV pathology, especially at slight-moderate phases of renal dysfunction (2). Besides such factors, the higher incidence of CV events in CRF patients than in the general population is attributed to the simultaneous presence of non-traditional CV factors associated with renal impairment (3). The prevalence of such factors grows as renal function declines. They include disturbances of the calcium-phosphorus metabolism, malnutrition, extracellular volume expansion, inflammation, increased oxidative stress, hyperhomocysteinemia, prothrombotic condition, and vascular rigidity (4).

In the case of CV disease in uremia, the role of the red blood cells (RBCs) tends only to be considered in relation to a change in their number. This typical and frequent clinical sign of uremia is rated a non-traditional CV risk factor in CRF (4). However, uremic RBCs may have a broader role in the CV system since in the uremic milieu erythrocytes are prone to many alterations, which may adversely affect the CV system.

The present review will comment on the main qualitative erythrocyte alterations and their potential pathophysiologic role in the uremic patient's CV risk status.

\section{Evidence Acquisition}

We systematically searched for studies published in English in the MEDLINE (from 1956 to 2016). For this search, we used the following terms in various combinations: chronic kidney disease, end stage renal disease, red blood cells, erythrocytes, inflammation, oxidative stress, cardiovascular disease, atherosclerosis, uremia, hemodialysis, nitric oxide, cyclic guanosine monophosphate, phosphatidylserine, endothelial cells, platelets, and anemia.

\section{Results}

The main studies that have reported RBC alteration in chronic renal failure are described below. 


\subsection{Altered Composition of the Erythrocyte Cell Membrane}

The RBC is a fairly simple cell devoid of a nucleus; its main components are cell membrane and hemoglobinrich cytoplasm. The cell membrane composition modulates the erythrocyte's visco-elastic properties, which are fundamental to survival of the cell in the stream of the circulation. Deformability is an intrinsic characteristic of normal RBCs, enabling them to pass down tiny capillaries and release oxygen. If they become less deformable, this triggers hemolysis in the capillaries and premature sequestration of RBCs by the reticulo-endothelial system (5), altering tissue oxygenation (6).

One of the far from negligible pathogenic features of anemia in the chronic kidney sufferers is the significant shortening of the circulating RBCs' half-life time (7). It is conjectured that this is essentially due to the toxic action of the uremic plasma environment upon the RBCs (8). It is indeed well known that when healthy donors' RBCs are re-infused into uremic patients, their survival declines significantly (9). Shortening of the half-life not only means a drop in the quantity of circulating hemoglobin - a parameter normally used to measure the severity of anemia - but also shows the difficulty the uremic patient's RBCs have in properly perfusing the microcirculation, precisely because of their altered rheologic properties (10).

It is of interest that recent studies have shown an altered protein composition in the uremic erythrocyte membrane, which especially affects protein components in the cytoskeletal network. In particular, in RBCs from patients on maintenance hemodialysis treatment, analysis of the expression of certain key proteins of the erythrocyte membrane has especially brought to light the low level of spectrine (11). A more recent unbiased study designed to assess CRF patients' erythrocyte membrane composition by proteomics revealed some significant variations in many proteins such as beta-adducin, tropomodulin-1, ezrin, and radixin (12). The cytoskeletal network is a chief factor behind RBCs' visco-elastic properties such as deformability (13). Such alterations in the membrane protein component $(11,12)$ might thus be part of the pathogenesis affecting erythrocyte deformability as observed in $\operatorname{CRF}(5,14)$.

One compound that has a beneficial effect on RBC rheology is carnitine. Especially when this important cofactor in the beta-oxidation of fatty acids is present in concentrations greater than normal, it is able to affect the biophysical and visco-elastic properties of the cell membrane (10). By techniques of ectacytometry, we have observed that carnitine can increase cell membrane elasticity, an effect that is somehow linked to carnitine's interaction with some protein components of the membrane-skeleton (15). It would appear that carnitine is able to strengthen the bonds among the proteins that form the cytoskeleton, and that such action is responsible for increasing membrane elasticity, which in turn improves RBC rheology. In support of these experimental findings, it has also been observed that carnitine significantly enhances interaction among membrane-skeleton proteins within the cell membrane (16).

The finding that there is a significant inverse correlation between membrane fluidity (an index of deformability) and the erythropoietin (EPO) dosage needed by hemodialysis patients seems to suggest that differing degrees of alteration in the uremic RBC's mechanical properties may closely affect the dosage of EPO required (14).

To date, there is no direct clinical evidence to indicate that changes in the rheologic properties of the RBCs increase the $\mathrm{CV}$ risk run by uremic patients. However, one recent preclinical experience suggests that rat RBCs preserved for 2 weeks at $4^{\circ} \mathrm{C}$ are less effective in ensuring normal oxygenation in the microcirculation than nonpreserved RBCs (17). Now, it is known that blood bankstored RBCs for transfusion are prone to various alterations (18); these involve the RBC membrane-skeleton and rheologic properties to an extent similar to the defects found in uremic patients' RBCs (19). Such alterations might explain not only the above-mentioned experimental observation as to the microcirculation oxygenation, but also some potential hypoxic effects to the coronary microcirculation and attendant $\mathrm{CV}$ risk.

The uremic erythrocyte membrane is altered not just in its protein, but in its phospholipid component. Human RBC phospholipids are normally distributed asymmetrically in the double layer of the cell membrane, and keeping such asymmetry is a physiologically important process for the cell. Loss of normal asymmetry indeed may have many pathophysiologic implications, especially when the aminophospholipid phosphatidylserine (PS) gets exposed on the cell surface instead of its usual location on the inner face of the membrane (20). It may generate a signal recognized by the macrophages and thereafter the cell be phagocytosed and removed from the circulation (21). This accelerated suicide mechanism on the part of the erythrocyte is termed eryptosis (22); it is thought to hold in vivo importance in the diminished survival of sickle-shaped RBCs (23).

The RBCs of chronic renal sufferers (whether on dialysis or on conservative management) have PS more exposed on the outer face of the cell (24). As residual renal function declines, this alteration gradually accentuates and is boosted by compounds pathologically present in uremic plasma (24), including beta-2 microglobulin (25), acrolein (26), and indoxyl sulphate (27). Extracorporeal dialysis may reduce the ability of uremic plasma to induce erythrocytes' PS exposure, and this is even more significant 
when techniques are used that have a broader range of removal than conventional hemodialysis, such as hemodiafiltration (28). Again, L-carnitine has been proven in vitro to reduce PS exposure on uremic patients' RBCs thanks to its antioxidant action (29); this may at least partly explain the increased erythrocyte survival observed in hemodialysis patients when treated with this compound for 24 weeks (30).

What is more, the increased exposure of PS on the erythrocytes may contribute to the anemia found in CRF (31). It has been shown in this connection that the presence of PS makes uremic RBCs susceptible to phagocytosis by human macrophages (32), which may lie behind the diminished erythrocyte survival in uremia (7). Not being fully integrated into the dosage algorithms, the diminished RBC half-life in uremia might have a role in the erythropoietic response to EPO (33), prompting the phenomenon of hemoglobin variability (34) which has been associated with increased risk of mortality in uremic patients (35).

The exposure of PS on the outer leaflet of the RBC membrane may also play a role in the coagulation process by promoting the assembly of two coagulation factor complexes, the prothrombinase complex and the tenase complex, leading to thrombin generation (36). Perturbations in RBC PS exposure are seen as a pathogenic mechanism for the prothrombotic state of beta-thalassemia and sickle cell disease (37). Chronic uremia is associated with an increased risk of thrombotic complications, which may represent the predominant cause of mortality particularly in dialysis patients (38). This thrombophilia is considered as being multifactorial (39), but mechanisms specific to uremia promoting hypercoagulability remain to be yet identified (40).

Recent evidence indicate that uremic erythrocytes may display a pathological pro-coagulant phenotype (40, 41). A role for surface-exposed PS in the increased pro-coagulant activity of uremic RBC is suggested by significant correlations between PS levels and (i) prothrombinase activation, (ii) plasma levels of thrombin generation markers, (iii) plasma levels of fibrinolysis markers and, (iv) thrombotic events in a 3-year retrospective analysis (41). Furthermore, preincubation of uremic RBCs with annexin V(41) or with lactadherin (40), which have a propensity for binding to PS rendering it unavailable for PS-mediated processes, strongly inhibited RBC pro-coagulant activity. Erythrocytepromoted hypercoagulability may also result from the cell release of vesicles called microparticles, which expose PS and express membrane antigens on their surface. It has been recently shown that circulating levels of RBC-derived pro-coagulant microparticles significantly increase in uremic patients compared to healthy subjects (40).

Based on these findings, one may reasonably assume that abnormal RBC PS exposure might have a part in the induction of a hypercoagulable state in uremic patients. Alternatively, RBC PS exposure could represent in these patients a new marker or a predictor of clinical thrombosis.

\subsection{Altered Erythrocyte Enzymatic Activity}

3.2.1. Diminished Erythrocyte Activity in the Intracellular Antioxidant System

The term "oxidative stress" covers a set of alterations affecting tissue, cells and macromolecules once a disequilibrium sets in between excessive production of anti-oxidant agents and an inadequate antioxidant defense mechanism. That these systems should be correctly balanced (socalled ox-redox equilibrium) is essential to a whole range of physiological functions in our organism.

Pro-oxidant substances are highly reactive compounds having a half-life of a few seconds. When these hydroxyl radicals interact inside the cell environment with the chief biological macromolecules (e.g., lipids, proteins, carbohydrates, and nucleic acids) they permanently modify the structure and function of these molecules, and are hence potential agents for CV damage (42).

When renal function is diminished, there is increased circulation of free oxygen radicals (reactive oxygen species, ROS) to an extent proportional to the level of glomerular filtrate (43). A rise in ROS oxidizes the oxyhemoglobin and forms hydrogen peroxide $\left(\mathrm{H}_{2} \mathrm{O}_{2}\right)$ and methemoglobin, which are responsible for tissue hypoxia (44). The presence of too many ROS also causes lipid peroxidation, resulting in permanent oxidative alterations in the lipoproteins (45). Some of these are intensely atherogenic such as malonyldialdehyde, the final products of advanced glycation or the protein products of advanced oxidation; they trigger the atherosclerotic process and damage the intimal wall of the arteries, causing a vascular inflammatory response and expression of leucocyte adhesion molecules, followed by migration of inflammatory cells into the sub-endothelial space. Oxidized LDL, in its turn, stimulates the formation of foamy cells and releases into circulation a great number of pro-inflammatory cytokines, which may destabilize plaque and increase the risk of ischemic cardiomyopathy $(46,47)$.

The lipid damage brought about by ROS via peroxidation may alter the integrity of the erythrocyte membrane, reducing cell half-life (48). Notably, RBCs may themselves contribute to uremic oxidative stress via alterations in the cellular enzymes that act upon the redox equilibrium. In CRF, one notes, significantly, a marked increase in the activity of glutathione peroxidase and glutathione reductase (pro-oxidant enzymes), as well as a significant reduction in superoxide dismutase and catalase (enzymes with antioxidant properties) (49). 
Again, in uremia the erythrocyte enzyme activity may be affected by the hemodialysis treatment. Interestingly, it has been observed that using vitamin E-enriched membranes significantly improves the erythrocyte activity of superoxide dismutase (50) and the deformability of RBCs (51), which reduces the need for EPO. By using such filters along with vitamin C (250 $\mathrm{mg}$ iv) for two months it also proved possible to reduce intradialytic hemolysis and oxidative damage to the RBCs (52). What is more, glucose levels in the dialyzer fluid may play an important role in regulating the erythrocyte antioxidant capacity. Bober et al. have shown that a glucose concentration of $5.6 \mathrm{mmol} / \mathrm{L}$ increases the exose monophosphate cycle in the erythrocytes, which benefits the antioxidant system and reduces the risk of hemolysis (53).

Concerning the use of antioxidant agents, Usberti and colleagues demonstrated how intravenous administration of $1200 \mathrm{mg}$ of reduced glutathione (GSH) at the end of each hemodialysis session over a span of not less than 9 months enabled 28 dialysis patients (14 of them on EPO treatment) to significantly improve erythrocyte survival and enhance the uremic picture (54). Oral administration of $600 \mathrm{mg} /$ die over a period of 14 months enabled 36 dialysis patients to increase the erythrocyte activity of superoxide dismutase vis-à-vis healthy controls, suggesting it had a protective role (55). When uremic patients on replacement therapy (34 on hemodialysis, 13 on peritoneal dialysis) took $300 \mathrm{mg} /$ die of vitamin $\mathrm{E}$ for 20 weeks, it proved to be associated with improvement of the erythrocyte osmotic fragility (56). However, other studies have failed to confirm the efficacy of vitamin $\mathrm{E}$ in modifying the erythrocyte antioxidant activity in dialysis patients (57).

\subsubsection{Altered Erythrocyte Nitric Oxide Production and Bioavail- ability}

Nitric oxide (NO) is a gaseous free radical produced by the Nitric Oxide Synthase (NOS), which is constitutively expressed in endothelial (eNOS) and neuronal (nNOS) tissues and is inducible (iNOS) in several tissues and cells under specific pathophysiological conditions. NO is known to be involved in the regulation of many intracellular signal pathways and exerts a wide pleiotropic action (58). At the vascular level, NO is a key molecule in the regulation of endothelium-mediated vasodilatation (59); also, it regulates several vascular mechanisms such as platelet aggregation, leukocyte adhesion to the endothelium and smooth muscle cells proliferation/migration, whose alterations represent crucial events in the onset and development of the atherosclerotic process (60).

In this regard, endothelial dysfunction is considered one of the main pathological mechanisms that may contribute to increased CV risk in CRF (61). In fact, reduced endothelium-dependent vasodilation and increased plasma levels of the endothelium-derived mediators have been reported in uremic patients (61-63). The impaired endothelium-dependent vasodilation in CRF patients suggests a reduction in the NO bioavailability (61). However, the mechanisms underlying this phenomenon, which is triggered by the uremic state, remain not well defined.

To date, circulating levels of NO were mainly attributed to that produced by the endothelium, and RBCs had been considered merely transporters of this gas. In fact, it is well known that erythrocytes bind to and inactivate NO produced in the endothelium through a rapid reaction with oxyhemoglobin to form methemoglobin, $S$ nitrosohemoglobin, and nitrates (64).

Under hypoxic conditions, RBCs play a key role in the release of NO, resulting in an NO-dependent vasodilation $(65,66)$, while under normal-oxygen or in various pathological conditions, the NO production/release by RBCs still needs to be better characterized. In this regard, the localization and function of the NOS in RBCs and in platelets were described for the first time in 2006 (67) although prior studies suggested the presence of this enzyme in RBCs $(66,68)$. In particular, in 2006, Kleinbongard and colleagues demonstrated the presence of an NOS-erythrocyte isoform, thus extending the role of RBC from merely transporters of NO to producers of such gas (67). Afterwards, the same authors hypothesized an RBC-NOS regulating mechanism comparable to that of endothelial NOS although mature RBCs lack cellular organelles which play a key role in the regulation of endothelial NOS (69). More recently, it has been demonstrated that RBCs are able to produce NO even in normal-oxygen condition through the activation of their endothelial isoform of NOS (70). Moreover, eNOS expression levels and activity in the RBCs of patients with coronary artery disease are significantly reduced as compared to RBCs of healthy subjects (71).

Interestingly, our group has recently published a study describing the possible mechanisms involved in the NO synthesis and bioavailability in RBCs from uremic patients (72). In particular, we assessed the enzymatic NO production in erythrocytes of patients on hemodialysis and compared it with that of healthy individuals.

Our study demonstrated that, in basal conditions, although RBC-NOS expression was lower in uremic RBCs, its phosphorylation levels in Serine-1177, NO production, and bioavailability (levels of cyclic guanosine monophosphate, cGMP) were significantly higher as compared to control RBCs. On the contrary, following RBCs stimulation with insulin or ionomycin (known to activate eNOS through a phosphorylation or calcium dependent mechanisms, respectively), the NO levels and its bioavailability were sig- 
nificantly higher in RBCs from healthy subjects compared to RBCs from hemodialysis patients, suggesting that uremic condition might reduce the response of RBC-NOS to further stimuli.

Our findings confirmed the presence of the eNOS isoform in erythrocytes (topic still highly debated and controversial) and identified, for the first time, an altered mechanism of eNOS activation in uremic RBCs (72). Interestingly, our data are supported by previous studies, which showed a marked increase in NO production in both erythrocytes and platelets from uremic patients on hemodialysis (73, 74). Moreover, a study published in 1982 (75) showed increased cGMP levels in RBCs from uremic patients compared to those from healthy subjects. This was confirmed in our recent study (72) where we demonstrated accumulating levels of cGMP in RBCs of subjects suffering from uremia, which was associated with a defective transport to the bloodstream of this nucleotide. In particular, we proved that this effect was associated with an impaired activity of erythrocyte cGMP membrane-transporter (multidrugresistance-associated protein-4, MRP4), whose levels of nitration and nitrosylation significantly increased under uremic conditions (72).

These data allow us to hypothesize that the erythrocyte intracellular cGMP levels might be a useful biomarker to monitor the uremic pro-oxidant and/or pro-inflammatory state associated with reduced vascular NO bioavailability in CRF.

\subsection{Abnormal Heterotypic Cell-Cell Interaction}

\subsubsection{RBC-Platelet Interaction}

Activated platelets may engage in dynamic interplay with other blood cellular elements such as erythrocytes $(76,77)$. By the use of flow cytometry and transmission electron microscopy, we first reported direct evidence of uremic platelet-RBC adherence in vitro and an increase in the number of circulating platelet-erythrocyte aggregates in chronic uremic patients (78). This observation seems attributable to both renal failure and hemodialysis treatment. Indeed, levels of platelet-RBC aggregates were higher in CRF patients not on dialysis than in healthy subjects but lower than in dialysis patients (78). In the latter, platelet-erythrocyte aggregates could rise still further during the hemodialysis session, mainly depending on the membrane material contained in the hemodialyzer $(78,79)$. Fibronectin might serve as a molecular bridge between adjacent platelets and RBCs (78).

Interactions between platelets and erythrocytes can markedly enhance in vitro several aspects of platelet reactivity $(80,81)$, and may be implicated in vivo in vascular abnormalities found in sickle cell disease $(76,77)$. Although atherosclerosis and vascular events are common in uremic patients, the significance of platelet-RBC aggregates in these patients remains yet to be elucidated.

\subsubsection{RBC-Endothelial Cell Interaction}

We have shown that RBCs from patients on hemodialysis have an increased propensity to adhere to human endothelial cell monolayers, possibly via a direct interaction between PS exposed on the external leaflet of the erythrocyte plasma membrane and thrombospondin in the subendothelial matrix (82). Interestingly, we observed that adhesion of RBCs from uremic patients to the vascular endothelium may modulate NO release by endothelial cultures (83), as previously demonstrated for sickle RBC (84). In cultured human endothelial cells, erythrocytes from uremic patients inhibited the eNOS expression (mRNA and protein), activity and, consequently, NO production, whereas erythrocytes from normal subjects had no such role (83). Defective eNOS is thought to represent a key parameter characterizing endothelial cell dysfunction, and in uremia it might have several consequences. Reduced NO production may be crucial to functional and structural vascular changes, promoted oxidative stress, and increased expression of adhesion molecules, resulting in endothelial damage and atherosclerosis (85) and therefore, it may play a role in elevated blood pressure (86).

The enhanced interaction between uremic RBC and the endothelium, besides the pro-inflammatory effects stemming from the reduced NO bioavailability, may also directly induce a vascular inflammatory phenotype (87). In fact, adherence of uremic RBCs to human endothelial cells induced a time-dependent up-regulation of vascular cell adhesion molecule- 1 and of intercellular adhesion molecules-1 (87), an early step in atherogenesis (46). Such increased vascular adhesion molecule expression was associated with mitogen-activated protein kinase activation and impaired protein kinase Akt phosphorylation, which are pro-inflammatory, NO-independent, signal transduction pathways $(88,89)$. In our experimental model $(87)$, the increase of endothelial adhesion molecule expression was supported by the remarkable enhanced adhesion of human monocytoid cells to endothelial cells cultured with uremic RBCs. These findings suggest that therapeutic strategies aimed at limiting the action of these pathways may have the potential to prevent and treat uremic vascular disease, a concept that deserves specific investigation.

\section{Conclusions}

The current review of literature has focused on the potential role of erythrocyte qualitative alterations in cardiovascular complications in CRF. On the basis of the afore- 

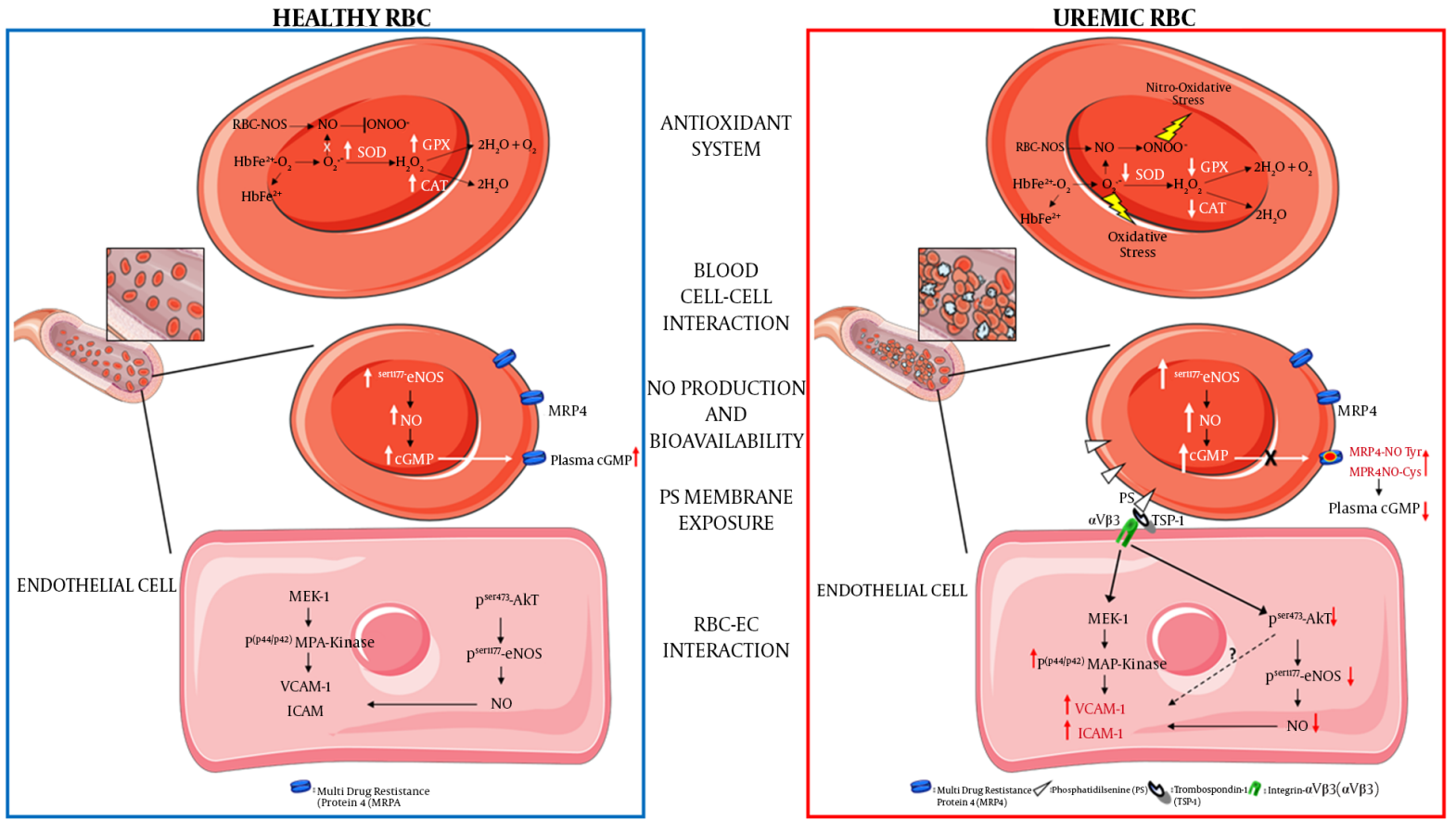

(a) Decreased antioxidant intracellular system: ROS in RBC is mainly generated by heme oxidation of oxyHb $\left(\mathrm{HbFe}^{2+}-\mathrm{O}_{2}\right)$ to metHb $\left(\mathrm{HbFe}^{2+}\right)$ and the release of superoxide anions $\left(\mathrm{O}^{-}\right)$. The presence of $\mathrm{O}^{-}$and its reaction with nitric oxide (NO) to generate peroxynitrite (ONOO- $)$can lead to increased oxidative and nitro-oxidative stress given that, in uremic condition, there is a functional failure of the main antioxidant enzymes such as superoxide dismutase (SOD) and catalase (CAT); (b) increased blood cellcell interaction: uremic RBCs show increased platelets and other blood cells interactions; (c) increased intracellular NO production and bioavailability: uremic RBC shows a compensatory increased phosphorylation levels of eNOS (endothelial Nitric Oxide Synthase) and NO production and an intra-erythrocyte accumulation of cGMP. This latter is due to a decreased activity of cGMP membrane transporter (MRP4, multidrug-resistance-associated protein-4) caused by rising levels of tyrosine nitration and cysteine nitrosylation of this transporter (MRP4-NOTyr and MRP4-NOCys). Such alterations reduce the plasmatic NO bioavailability thus contributing to an increased CV risk in CRF; (d) increased phosphatidylserine exposure: uremic RBC shows increased exposure levels of this membrane phospholipid; (e) increased RBC-endothelial cell (EC) interaction: the increased PS exposure promotes the adhesion of uremic RBC to the endothelium through the interaction with the thrombospondin- 1 (TSP-1) - integrin- $\alpha \mathrm{V} \beta 3$ ( $\alpha \mathrm{V} \beta 3$ ) complex. This interaction promotes in EC: (i) the activation of the pro-atherogenic MAP-Kinase (mitogenic-activator protein kinase) pathway with increased expression of adhesion molecules such as VCAM-1 (vascular cellular adhesion molecule-1) and ICAM -1 (Intercellular adhesion molecule-1); (ii) the inhibition of the anti-atherogenic pathway resulting in decreased Akt-eNOS (Protein kinase B-eNOS) phosphorylation and reduced NO production and bioavailability.

mentioned findings, it is possible to suggest that erythrocytes in the uremic milieu undergo structural and functional impairments such as reduction of antioxidant activity and alteration of the production of nitric oxide, increased pro-coagulant activity and endothelium adhesion, modification in the composition of plasma membrane, all aspects which may jeopardize their properties.

These erythrocyte molecular transformations certainly can play an important role per se in understanding $\mathrm{RBC}$ role in the pathogenesis of vascular complication of uremia and, additionally, through them, it might be possible to identify potential erythrocyte biomarkers useful both for prevention and for monitoring of CV risk in CRF patients.

\section{Footnotes}

Conflict of Interests: The authors declare that they have no conflicts of interest.

Financial Disclosure: Dr. Arduini is an employee of CoreQuest. The other authors declare that they have no financial interests related to the material in the manuscript.

\section{References}

1. Go AS. Cardiovascular Disease Consequences of CKD. Semin Nephrol. 2016;36(4):293-304. doi: 10.1016/j.semnephrol.2016.05.006. [PubMed: 27475660].

2. Parikh NI, Hwang SJ, Larson MG, Meigs JB, Levy D, Fox CS. Cardiovascular disease risk factors in chronic kidney disease: overall burden and rates of treatment and control. Arch Intern Med. 2006;166(17):1884-91. doi: 10.1001/archinte.166.17.1884. [PubMed:17000946].

3. Zoccali C. Cardiovascular risk in uraemic patients-is it fully explained by classical risk factors?. Nephrol Dial Transplant. 2000;15(4):454-7. doi: 10.1093/ndt/15.4.454. [PubMed: 10727537]. 
4. van der Zee S, Baber U, Elmariah S, Winston J, Fuster V. Cardiovascular risk factors in patients with chronic kidney disease. Nat Rev Cardiol. 2009;6(9):580-9. doi: 10.1038/nrcardio.2009.121. [PubMed: 19621012].

5. Kikuchi Y, Koyama T, Koyama Y, Tozawa S, Arai T, Horimoto M, et al. Red blood cell deformability in renal failure. Nephron. 1982;30(1):8-14. doi: 10.1159/000182424. [PubMed: 7088236].

6. Fisher DJ, Burton DT, Yonkos LT, Turley SD, Ziegler GP, Turley BS. Derivation of acute ecological risk criteria for chlorite in freshwater ecosystems. Water Res. 2003;37(18):4359-68. doi: 10.1016/S00431354(03)00433-0. [PubMed: 14511706].

7. Ly J, Marticorena R, Donnelly S. Red blood cell survival in chronic renal failure. Am J Kidney Dis. 2004;44(4):715-9. doi: 10.1016/S02726386(04)00951-5. [PubMed: 15384023].

8. Bonomini M, Sirolli V. Uremic toxicity and anemia. J Nephrol. 2003;16(1):21-8. [PubMed: 12649531].

9. Joske RA, McAlister JM, Prankerd TA. Isotope investigations of red cell production and destruction in chronic renal disease. Clin Sci. 1956;15(4):511-22. [PubMed: 13374936].

10. Bonomini M, Zammit V, Pusey CD, De Vecchi A, Arduini A. Pharmacological use of L-carnitine in uremic anemia: has its full potential been exploited?. Pharmacol Res. 2011;63(3):157-64. doi: 10.1016/j.phrs.2010.11.006. [PubMed: 21138768].

11. Costa E, Rocha S, Rocha-Pereira P, Castro E, Miranda V, do Sameiro Faria M, et al. Altered erythrocyte membrane protein composition in chronic kidney disease stage 5 patients under haemodialysis and recombinant human erythropoietin therapy. Blood Purif. 2008;26(3):267-73. doi: 10.1159/000126922. [PubMed: 18417959].

12. Alvarez-Llamas G, Zubiri I, Maroto AS, de la Cuesta F, Posada-Ayala M, Martin-Lorenzo M, et al. A role for the membrane proteome in human chronic kidney disease erythrocytes. Transl Res. 2012;160(5):374-83. doi: 10.1016/j.trsl.2012.06.004. [PubMed: 22814359].

13. Evans EA, Hochmuth RM. Membrane viscoelasticity. Biophys J. 1976;16(1):1-11. doi: 10.1016/S0006-3495(76)85658-5. [PubMed: 1244886].

14. Linde T, Sandhagen B, Wikstrom B, Danielson BG. The required dose of erythropoietin during renal anaemia treatment is related to the degree of impairment in erythrocyte deformability. Nephrol Dial Transplant. 1997;12(11):2375-9. doi: 10.1093/ndt/12.11.2375. [PubMed: 9394325].

15. Arduini A, Rossi M, Mancinelli G, Belfiglio M, Scurti R, Radatti G, et al. Effect of L-carnitine and acetyl-L-carnitine on the human erythrocyte membrane stability and deformability. Life Sci. 1990;47(26):2395-400. doi: 10.1016/0024-3205(90)90483-8. [PubMed: 2263166].

16. Butterfield DA, Rangachari A. Acetylcarnitine increases membrane cytoskeletal protein-protein interactions. Life Sci. 1993;52(3):297-303. doi:10.1016/0024-3205(93)90221-N. [PubMed: 8380879].

17. Gonzalez AM, Yazici I, Kusza K, Siemionow M. Effects of fresh versus banked blood transfusions on microcirculatory hemodynamics and tissue oxygenation in the rat cremaster model. Surgery. 2007;141(5):630-9. doi: 10.1016/j.surg.2006.09.015. [PubMed: 17462463].

18. Hoehn RS, Jernigan PL, Chang AL, Edwards MJ, Pritts TA. Molecular mechanisms of erythrocyte aging. Biol Chem. 2015;396(6-7):621-31. doi: 10.1515/hsz-2014-0292. [PubMed: 25803075].

19. Georgatzakou HT, Antonelou MH, Papassideri IS, Kriebardis AG. Red blood cell abnormalities and the pathogenesis of anemia in endstage renal disease. Proteomics Clin Appl. 2016;10(8):778-90. doi: 10.1002/prca.201500127. [PubMed: 26948278].

20. Zwaal RF, Schroit AJ. Pathophysiologic implications of membrane phospholipid asymmetry in blood cells. Blood. 1997;89(4):1121-32. [PubMed: 9028933].

21. Schroit AJ, Madsen JW, Tanaka Y. In vivo recognition and clearance of red blood cells containing phosphatidylserine in their plasma membranes. J Biol Chem. 1985;260(8):5131-8. [PubMed: 3988747].

22. Lang E, Qadri SM, Lang F. Killing me softly - suicidal erythrocyte death. Int J Biochem Cell Biol. 2012;44(8):1236-43. doi: 10.1016/j.biocel.2012.04.019. [PubMed: 22561748].

23. Wood BL, Gibson DF, Tait JF. Increased erythrocyte phosphatidylserine exposure in sickle cell disease: flow-cytometric measurement and clinical associations. Blood. 1996;88(5):1873-80. [PubMed: 8781447].

24. Bonomini M, Sirolli V, Settefrati N, Dottori S, Di Liberato L, Arduini A. Increased erythrocyte phosphatidylserine exposure in chronic renal failure. J Am Soc Nephrol. 1999;10(9):1982-90. [PubMed: 10477151].

25. Pavone B, Bucci S, Sirolli V, Merlini G, Del Boccio P, Di Rienzo M, et al. Beta2-microglobulin causes abnormal phosphatidylserine exposure in human red blood cells. Mol Biosyst. 2011;7(3):651-8. doi: 10.1039/comb00137f. [PubMed: 21107472].

26. Ahmed MS, Langer H, Abed M, Voelkl J, Lang F. The uremic toxin acrolein promotes suicidal erythrocyte death. Kidney Blood Press Res. 2013;37(2-3):158-67. doi: 10.1159/000350141. [PubMed: 23712027].

27. Ahmed MS, Abed M, Voelkl J, Lang F. Triggering of suicidal erythrocyte death by uremic toxin indoxyl sulfate. BMC Nephrol. 2013;14:244. doi: 10.1186/1471-2369-14-244. [PubMed: 24188099].

28. Bonomini M, Ballone E, Di Stante S, Bucciarelli T, Dottori S, Arduini A, et al. Removal of uraemic plasma factor(s) using different dialysis modalities reduces phosphatidylserine exposure in red blood cells. Nephrol Dial Transplant. 2004;19(1):68-74. doi: 10.1093/ndt/gfg532. [PubMed: 14671041].

29. Sun Y, Liu G, Li X, Shi Y, Guan G. L-Carnitine inhibits eryptosis induced by uremic serum and the related mechanisms. Ren Fail. 2015;37(6):1050-6. doi:10.3109/0886022X.2015.1052977.[PubMed: 26358151].

30. Arduini A, Bonomini M, Clutterbuck EJ, Laffan MA, Pusey CD. Effect of L-carnitine administration on erythrocyte survival in haemodialysis patients. Nephrol Dial Transplant. 2006;21(9):2671-2. doi: 10.1093/ndt/gfl155. [PubMed: 16611680].

31. Kong QY, Wu X, Li J, Peng WX, Ye R, Lindholm B, et al. Loss of phospholipids asymmetry in red blood cells contributes to anemia in uremic patients. Adv Perit Dial. 2001;17:58-60. [PubMed: 11510298].

32. Bonomini M, Sirolli V, Reale M, Arduini A. Involvement of phosphatidylserine exposure in the recognition and phagocytosis of uremic erythrocytes. Am J Kidney Dis. 2001;37(4):807-14. [PubMed: 11273881].

33. Kalicki RM, Uehlinger DE. Red cell survival in relation to changes in the hematocrit: more important than you think. Blood Purif. 2008;26(4):355-60. doi: 10.1159/000133838. [PubMed: 18493121].

34. Kalantar-Zadeh K, Aronoff GR. Hemoglobin variability in anemia of chronic kidney disease. J Am Soc Nephrol. 2009;20(3):479-87. doi: 10.1681/ASN.2007070728. [PubMed: 19211716].

35. Yang W, Israni RK, Brunelli SM, Joffe MM, Fishbane S, Feldman HI. Hemoglobin variability and mortality in ESRD. $J$ Am Soc Nephrol. 2007;18(12):3164-70. doi: 10.1681/ASN.2007010058. [PubMed: 18003781].

36. Vance JE, Steenbergen R. Metabolism and functions of phosphatidylserine. Prog Lipid Res. 2005;44(4):207-34. doi: 10.1016/j.plipres.2005.05.001. [PubMed: 15979148].

37. Helley D, Eldor A, Girot R, Ducrocq R, Guillin MC, Bezeaud A. Increased procoagulant activity of red blood cells from patients with homozygous sickle cell disease and beta-thalassemia. Thromb Haemost. 1996;76(3):322-7. [PubMed: 8883264].

38. Pavord S, Myers B. Bleeding and thrombotic complications of kidney disease. Blood Rev. 2011;25(6):271-8. doi: 10.1016/j.blre.2011.07.001. [PubMed: 21872374].

39. Shashar M, Francis J, Chitalia V. Thrombosis in the uremic milieuemerging role of "thrombolome". Semin Dial. 2015;28(2):198-205. doi: 10.1111/sdi.12255. [PubMed: 24962903].

40. Gao C, Xie R, Yu C, Ma R, Dong W, Meng H, et al. Thrombotic Role of Blood and Endothelial Cells in Uremia through Phosphatidylserine Exposure and Microparticle Release. PLoS One. 2015;10(11):e0142835. doi: 10.1371/journal.pone.0142835. [PubMed: 26580207].

41. Bonomini M, Sirolli V, Merciaro G, Antidormi T, Di Liberato L, Brum- 
mer U, et al. Red blood cells may contribute to hypercoagulability in uraemia via enhanced surface exposure of phosphatidylserine. Nephrol Dial Transplant. 2005;20(2):361-6. doi: 10.1093/ndt/gfh622. [PubMed: 15598665].

42. Locatelli F, Canaud B, Eckardt KU, Stenvinkel P, Wanner C, Zoccali C. Oxidative stress in end-stage renal disease: an emerging threat to patient outcome. Nephrol Dial Transplant. 2003;18(7):1272-80. doi: 10.1093/ndt/gfg074. [PubMed:12808161].

43. Kao MP, Ang DS, Pall A, Struthers AD. Oxidative stress in renal dysfunction: mechanisms, clinical sequelae and therapeutic options. J Hum Hypertens. 2010;24(1):1-8. doi: 10.1038/jhh.2009.70. [PubMed: 19727125].

44. D'Agnillo F, Alayash AI. Redox cycling of diaspirin cross-linked hemoglobin induces G2/M arrest and apoptosis in cultured endothelial cells. Blood. 2001;98(12):3315-23. doi: 10.1182/blood.V98.12.3315. [PubMed: 11719369].

45. Kaysen GA. The microinflammatory state in uremia: causes and potential consequences. J Am Soc Nephrol. 2001;12(7):1549-57. [PubMed: 11423586].

46. Hansson GK. Inflammatory mechanisms in atherosclerosis. J Thromb Haemost. 2009;7 Suppl 1:328-31. doi: 10.1111/j.1538-7836.2009.03416.x. [PubMed: 19630827].

47. Di Pietro N, Formoso G, Pandolfi A. Physiology and pathophysiology of oxLDL uptake by vascular wall cells in atherosclerosis. Vascul Pharmacol. 2016;84:1-7. doi:10.1016/j.vph.2016.05.013. [PubMed: 27256928].

48. Ayala A, Munoz MF, Arguelles S. Lipid peroxidation: production, metabolism, and signaling mechanisms of malondialdehyde and 4-hydroxy-2-nonenal. Oxid Med Cell Longev. 2014;2014:360438. doi: 10.1155/2014/360438. [PubMed: 24999379].

49. Sindhu RK, Ehdaie A, Farmand F, Dhaliwal KK, Nguyen T, Zhan $\mathrm{CD}$, et al. Expression of catalase and glutathione peroxidase in renal insufficiency. Biochim Biophys Acta. 2005;1743(1-2):86-92. doi: 10.1016/j.bbamcr.2004.08.013. [PubMed: 15777843].

50. Bargnoux AS, Cristol JP, Jaussent I, Chalabi L, Bories P, Dion JJ, et al. Vitamin E-coated polysulfone membrane improved red blood cell antioxidant status in hemodialysis patients. J Nephrol. 2013;26(3):55663. doi: 10.5301/jn.5000195. [PubMed: 22956433].

51. Kobayashi S, Moriya H, Aso K, Ohtake T. Vitamin E-bonded hemodialyzer improves atherosclerosis associated with a rheological improvement of circulating red blood cells. Kidney Int. 2003;63(5):1881-7. doi: 10.1046/j.1523-1755.2003.00920.x. [PubMed: 12675867].

52. Yang CC, Hsu SP, Wu MS, Hsu SM, Chien CT. Effects of vitamin $\mathrm{C}$ infusion and vitamin E-coated membrane on hemodialysisinduced oxidative stress. Kidney Int. 2006;69(4):706-14. doi: 10.1038/sj.ki.5000109. [PubMed:16395251].

53. Bober J, Kedzierska K, Kwiatkowska E, Stachowska E, Golembiewska E, Mazur O, et al. Does oxidative stress affect the activity of the sodiumproton exchanger?. Ann Acad Med Stetin. 2010;56(3):5-12. [PubMed: 22053621].

54. Usberti M, Lima G, Arisi M, Bufano G, D’Avanzo L, Gazzotti RM. Effect of exogenous reduced glutathione on the survival of red blood cells in hemodialyzed patients. J Nephrol. 1997;10(5):261-5. [PubMed: 9364318].

55. Giray B, Kan E, Bali M, Hincal F, Basaran N. The effect of vitamin E supplementation on antioxidant enzyme activities and lipid peroxidation levels in hemodialysis patients. Clin Chim Acta. 2003;338(1-2):91-8. [PubMed: 14637272].

56. Uzum A, Toprak O, Gumustas MK, Ciftci S, Sen S. Effect of vitamin E therapy on oxidative stress and erythrocyte osmotic fragility in patients on peritoneal dialysis and hemodialysis. J Nephrol. 2006;19(6):739-45. [PubMed: 17173246].

57. Chen CK, Liaw JM, Juang JG, Lin TH. Antioxidant enzymes and trace elements in hemodialyzed patients. Biol Trace Elem Res. 1997;58(1-2):14957. doi: 10.1007/BF02910675. [PubMed: 9363329].

58. Michel T, Feron O. Nitric oxide synthases: which, where, how, and why?. J Clin Invest. 1997;100(9):2146-52. doi: 10.1172/JCI119750.
[PubMed: 9410890].

59. Palmer RM, Ferrige AG, Moncada S. Nitric oxide release accounts for the biological activity of endothelium-derived relaxing factor. Nature. 1987;327(6122):524-6. doi: 10.1038/327524a0. [PubMed: 3495737].

60. Behrendt D, Ganz P. Endothelial function. From vascular biology to clinical applications. Am J Cardiol. 2002;90(10C):40L-8L. doi: 10.1016/S0002-9149(02)02963-6. [PubMed: 12459427].

61. Morris ST, Jardine AG. The vascular endothelium in chronic renal failure. J Nephrol. 2000;13(2):96-105. [PubMed:10858970].

62. Bonomini M, Reale M, Santarelli P, Stuard S, Settefrati N, Albertazzi A. Serum levels of soluble adhesion molecules in chronic renal failure and dialysis patients. Nephron. 1998;79(4):399-407. doi 10.1159/000045084. [PubMed: 9689154].

63. Stam F, van Guldener C, Schalkwijk CG, ter Wee PM, Donker AJ, Stehouwer CD. Impaired renal function is associated with markers of endothelial dysfunction and increased inflammatory activity. Nephrol Dial Transplant. 2003;18(5):892-8. doi: 10.1093/ndt/gfg080. [PubMed: 12686661].

64. Kim-Shapiro DB, Schechter AN, Gladwin MT. Unraveling the reactions of nitric oxide, nitrite, and hemoglobin in physiology and therapeutics. Arterioscler Thromb Vasc Biol. 2006;26(4):697-705. doi: 10.1161/01.ATV.0000204350.44226.9a. [PubMed: 16424350].

65. Webb AJ, Milsom AB, Rathod KS, Chu WL, Qureshi S, Lovell MJ, et al Mechanisms underlying erythrocyte and endothelial nitrite reduction to nitric oxide in hypoxia: role for xanthine oxidoreductase and endothelial nitric oxide synthase. Circ Res. 2008;103(9):957-64. doi: 10.1161/CIRCRESAHA.108.175810. [PubMed:18818408].

66. Chen LY, Mehta JL. Evidence for the presence of L-arginine-nitric oxide pathway in human red blood cells: relevance in the effects of red blood cells on platelet function. J Cardiovasc Pharmacol. 1998;32(1):5761. doi: 10.1097/00005344-199807000-00009. [PubMed: 9676721].

67. Kleinbongard P, Schulz R, Rassaf T, Lauer T, Dejam A, Jax T, et al. Red blood cells express a functional endothelial nitric oxide synthase. Blood. 2006;107(7):2943-51. doi:10.1182/blood-2005-10-3992. [PubMed: 16368881].

68. Jubelin BC, Gierman JL. Erythrocytes may synthesize their own nitric oxide. Am J Hypertens. 1996;9(12 Pt 1):1214-9. doi: 10.1016/S0895 7061(96)00257-9. [PubMed: 8972893].

69. Ozuyaman B, Grau M, Kelm M, Merx MW, Kleinbongard P. RBC NOS: regulatory mechanisms and therapeutic aspects. Trends $\mathrm{Mol}$ Med. 2008;14(7):314-22. doi:10.1016/j.molmed.2008.05.002. [PubMed: 18539530].

70. Cortese-Krott MM, Rodriguez-Mateos A, Sansone R, Kuhnle GG Thasian-Sivarajah S, Krenz T, et al. Human red blood cells at work: identification and visualization of erythrocytic eNOS activity in health and disease. Blood. 2012;120(20):4229-37. doi: 10.1182/blood2012-07-442277. [PubMed: 23007404].

71. Eligini S, Porro B, Lualdi A, Squellerio I, Veglia F, Chiorino E, et al. Nitric oxide synthetic pathway in red blood cells is impaired in coronary artery disease. PLoS One. 2013;8(8):ee66945. doi: 10.1371/journal.pone.0066945. [PubMed: 23940508].

72. Di Pietro N, Giardinelli A, Sirolli V, Riganti C, Di Tomo P, Gazzano E, et al. Nitric oxide synthetic pathway and cGMP levels are altered in red blood cells from end-stage renal disease patients. Mol Cell Biochem. 2016;417(1-2):155-67. doi: 10.1007/s11010-016-2723-0. [PubMed: 27206740]

73. Reis PF, da Silva CD, Brunini TM, Moss MB, Siqueira MA, Santos SF, et al. Plasma amino acid profile and L-arginine uptake in red blood cells from malnourished uremic patients. J Ren Nutr. 2006;16(4):32531. doi: 10.1053/j.jrn.2006.04.024. [PubMed: 17046616].

74. Siqueira MA, Brunini TM, Pereira NR, Martins MA, Moss MB, Santos $\mathrm{SF}$, et al. Increased nitric oxide production in platelets from severe chronic renal failure patients. Can J Physiol Pharmacol. 2011;89(2):97102. doi: 10.1139/y10-111. [PubMed: 21326340].

75. DeBari VA, Bennun A. Cyclic GMP in the human erythrocyte. Intracel- 
lular levels and transport in normal subjects and chronic hemodialysis patients. Clin Biochem. 1982;15(4):219-21. doi: 10.1016/S00099120(82)90160-6. [PubMed: 6290101].

76. Wun T, Paglieroni T, Tablin F, Welborn J, Nelson K, Cheung A. Platelet activation and platelet-erythrocyte aggregates in patients with sickle cell anemia. J Lab Clin Med. 1997;129(5):507-16. doi: 10.1016/S0022 2143(97)90005-6. [PubMed: 9142047].

77. Wun T, Paglieroni T, Field CL, Welborn J, Cheung A, Walker NJ, et al. Platelet-erythrocyte adhesion in sickle cell disease. J Investig Med. 1999;47(3):121-7. [PubMed: 10198567].

78. Sirolli V, Strizzi L, Di Stante S, Robuffo I, Procopio A, Bonomini M. Platelet activation and platelet-erythrocyte aggregates in endstage renal disease patients on hemodialysis. Thromb Haemost 2001;86(3):834-9. [PubMed: 11583316].

79. Sirolli V, Ballone E, Di Stante S, Amoroso L, Bonomini M. Cell activation and cellular-cellular interactions during hemodialysis: effect of dialyzer membrane. Int J Artif Organs. 2002;25(6):529-37. [PubMed 12117292].

80. Santos MT, Valles J, Marcus AJ, Safier LB, Broekman MJ, Islam $\mathrm{N}$, et al. Enhancement of platelet reactivity and modulation of eicosanoid production by intact erythrocytes. A new approach to platelet activation and recruitment. J Clin Invest. 1991;87(2):571-80. doi: 10.1172/JCI115032. [PubMed: 1991840].

81. Valles J, Santos MT, Aznar J, Marcus AJ, Martinez-Sales V, Portoles M et al. Erythrocytes metabolically enhance collagen-induced platelet responsiveness via increased thromboxane production, adenosine diphosphate release, and recruitment. Blood. 1991;78(1):154-62. [PubMed: 1712639].

82. Bonomini M, Sirolli V, Gizzi F, Di Stante S, Grilli A, Felaco M. Enhanced adherence of human uremic erythrocytes to vascular endothelium: role of phosphatidylserine exposure. Kidney Int. 2002;62(4):1358-63. doi:10.1111/j.1523-1755.2002.kid560.x. [PubMed:12234306]
83. Bonomini M, Pandolfi A, Di Pietro N, Sirolli V, Giardinelli A, Consoli A, et al. Adherence of uremic erythrocytes to vascular endothelium decreases endothelial nitric oxide synthase expression. Kidney Int. 2005;67(5):1899-906. doi: 10.1111/j.1523-1755.2005.00288.x. [PubMed: 15840037].

84. Mosseri M, Bartlett-Pandite AN, Wenc K, Isner JM, Weinstein R. Inhibition of endothelium-dependent vasorelaxation by sickle erythrocytes. Am Heart J. 1993;126(2):338-46. [PubMed: 8338004].

85. Naruse K, Shimizu K, Muramatsu M, Toki Y, Miyazaki Y, Okumura K, et al. Long-term inhibition of NO synthesis promotes atherosclerosis in the hypercholesterolemic rabbit thoracic aorta. PGH2 does not contribute to impaired endothelium-dependent relaxation. Arterioscler Thromb. 1994;14(5):746-52. [PubMed: 8172852].

86. Xiao S, Schmidt RJ, Baylis C. Plasma from ESRD patients inhibits nitric oxide synthase activity in cultured human and bovine endothelial cells. Acta Physiol Scand. 2000;168(1):175-9. doi: 10.1046/j.1365201x.2000.00640.x. [PubMed:10691797].

87. Pandolfi A, Di Pietro N, Sirolli V, Giardinelli A, Di Silvestre S, Amoroso L, et al. Mechanisms of uremic erythrocyte-induced adhesion of human monocytes to cultured endothelial cells. J Cell Physiol. 2007;213(3):699-709. doi:10.1002/jcp.21138. [PubMed: 17516566].

88. Madonna R, Pandolfi A, Massaro M, Consoli A, De Caterina R. Insulin enhances vascular cell adhesion molecule-1 expression in human cultured endothelial cells through a pro-atherogenic pathway mediated by p38 mitogen-activated protein-kinase. Diabetologia. 2004;47(3):532-6. doi: 10.1007/s00125-004-1330-x. [PubMed: 14762656].

89. Mukai Y, Rikitake Y, Shiojima I, Wolfrum S, Satoh M, Takeshita K, et al. Decreased vascular lesion formation in mice with inducible endothelial-specific expression of protein kinase Akt. J Clin Invest. 2006;116(2):334-43. doi: 10.1172/JCI26223. [PubMed: 16453020]. 